\title{
A CONSTITUIÇÃO DOS LIVROS DIDÁTICOS PELA DETERMINAÇÃO DAS TEORIAS LINGUÍSTICAS
}

Caroline M. Schneiders

(UFFS)

Cleiton Reisdorfer Silva

(UFSM)

\section{RESUMO}

No presente estudo, analisamos como as teorias linguísticas são retomadas e articuladas na constituição discursiva de materiais didáticos destinados ao ensino de Língua Portuguesa no Brasil. Buscamos explicitar, por meio de marcas linguísticas, a maneira como estas teorias linguísticas ressoam na discursividade destes materiais. Nosso corpus de análise é constituído por dois livros didáticos de Língua Portuguesa: i) um exemplar de circulação atual - Português Linguagens - $9^{\circ}$ Ano, de William Roberto Cereja e Thereza Cochar Magalhães; ii) um exemplar da década de oitenta

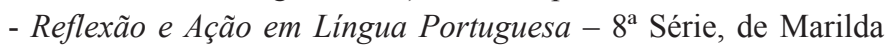
Prates. Entendemos os exemplares como materialidades linguísticas significantes, a fim de compreender a sua constituição e como esta afeta e determina o que pode e deve ser ensinado nas aulas de Língua Portuguesa e nas escolas. Para tanto, filiamo-nos aos pressupostos da História das Ideias Linguísticas, que, no Brasil, constitui-se vinculada à Análise de Discurso pecheuxtiana, e que nos auxiliou a realizar gestos interpretativos sobre o corpus. A partir da análise realizada, consideramos os Livros Didáticos como instrumentos linguísticos e compreendemos que permanece nessa materialidade uma forte presença do ensino com enfoque na gramática tradicional, mesmo com todos os avanços das teorias linguísticas. PALAVRAS-CHAVE: Análise de Discurso. Livros Didáticos. História das Ideias Linguísticas. 


\section{Introdução}

A preocupação com o estudo e análise dos materiais didáticos produzidos e distribuídos no Brasil não é recente e muitos são os pesquisadores que, sob diversos enfoques, direcionam seus trabalhos para essa área de estudos ${ }^{1}$. Acreditamos que isso se deva a uma necessidade constante de analisar, avaliar, (re)construir e qualificar a produção desses materiais didáticos e, de modo mais específico, buscar a capacitação de profissionais que os utilizam para uma compreensão mais adequada desse material, levando em conta seu papel como consumidores e utilizadores de livros de didáticos em situações de ensino/aprendizagem. Nesse âmbito, o Livro Didático de Língua Portuguesa (LDP) destaca-se por ser um material complementar ou de suporte para o ensino, que é, muitas vezes, o único a ser utilizado pelos professores.

Diversas são as razões para a extrema popularidade dos LDPs em nossas salas de aula e a valorização estatal é tamanha a ponto de ser expressa pela existência de um programa governamental, responsável pelo processo de avaliação e distribuição dos Livros Didáticos (LDs), o Programa Nacional do Livro Didático (PNLD). A adoção em larga escala do livro didático remonta, no Brasil, à década de 1950, momento em que teve início a chamada "democratização do ensino" em nosso país (SOARES, 2000).

Considerando essa importância que o LDP pode ter diante do ensino da Língua Portuguesa (LP), durante o transcorrer desse trabalho, buscamos enfatizá-lo enquanto uma materialidade linguística significante, a fim de compreender a sua constituição e, consequentemente, a maneira como sua constituição afeta e determina o que pode e deve e o que não pode e não deve ser ensinado nas aulas de Língua Portuguesa e nas escolas, tendo em vista que a escola é um Aparelho Ideológico do Estado (AIE) $)^{2}$ e que os LDs, ainda que produzidos de forma independente, atendem a uma série de critérios estabelecidos pelo Ministério da Educação e Cultura, tornando possível que seja mantido o controle estatal sobre a produção e distribuição destes materiais. Para tanto, torna-se relevante observar alguns aspectos que nos auxiliam na compreensão da constituição dessa materialidade, como, por exemplo, em quais concepções de língua e linguagem, sujeito e ensino a produção dos LDPs encontram-se ancorados. Partimos de tais noções, com vistas a analisar de modo mais específico a maneira como o desenvolvimento das ideias (teorias) linguísticas estão materializadas no fio do discurso, determinando a constituição dos LDPs. 
Para responder a essa questão, realizamos um recorte específico, selecionando para análise dois exemplares de livros didáticos, de modo a desenvolver uma análise comparativa: i) um exemplar de circulação atual: Português- Linguagens $-9^{\circ}$ Ano, de William Roberto Cereja e Thereza Cochar Magalhães; ii) um exemplar da década de oitenta, num período de mais de uma década antes da publicação dos Parâmetros Curriculares Nacionais, a saber: Reflexão e Ação em Língua Portuguesa - $8^{\text {a }}$ Série, de Marilda Prates.

Utilizamos como pressupostos teóricos, para análise e compreensão do material selecionado, conceitos advindos da Análise de Discurso (AD) de linha pecheuxtiana em sua relação com a História das Ideias Linguísticas (HIL). Partindo desse aporte teórico-metodológico, procuramos observar, por meio de marcas e regularidades linguísticas, o modo como o objeto de estudo é determinado pelas teorias linguísticas em circulação em dada conjuntura, considerando, portanto, a relação do discurso com a exterioridade, com suas condições de produção nos gestos de interpretação que serão produzidos.

\section{Um olhar discursivo sobre os Livros Didáticos}

Ao selecionarmos um objeto de estudo complexo como o LD, há a necessidade de situá-lo como uma materialidade linguística e histórica que passou por um processo de legitimação (CORACINI, 1999) e, consequentemente, de buscarmos um aporte teórico que leve em consideração essa materialidade. Ao reconhecer a legitimidade do LD, como instrumento utilizado como suporte para atividades de ensino e aprendizagem, devemos destacar a importância de dois elementos que interferem de forma decisiva nessa legitimação (CORACINI, 1999).

O primeiro elemento é a instituição escolar, que assume a responsabilidade social de formar cidadãos no mundo globalizado, levando em conta valores, cultura, história e demais patrimônios não mensuráveis de determinada sociedade. Assumindo esta responsabilidade, caberia à escola definir o que se pode ou não ensinar aos alunos, quais conhecimentos e valores transmitir e quais conteúdos abordar. O segundo elemento é a figura do professor, profissional este que é responsável por efetivar em sala de aula atividades de ensino que estejam de acordo com os objetivos que a escola se propõe a cumprir.

Em um ambiente de busca e construção de conhecimentos e de crescimento profissional e institucional, acreditamos que seria natural es- 
cola e professor determinarem-se mutuamente em um processo no qual os sentidos são reconstruídos a partir da experiência e da necessidade específica de cada escola e sua expressão se daria em documentos institucionais e nas próprias atividades docentes. Porém, como afirma Coracini (1999), frequentemente o LD constitui o centro do processo de ensino/ aprendizagem e escola e professores acabam por delegar ao LD a função de determinar quais conhecimentos, conteúdos e temas serão ensinados. Dentre as razões para este fato, citamos a crença de que o LD atua como um argumento de autoridade e de que o professor possui um nível de conhecimento abaixo daquele expresso no livro (CORACINI, 1999).

Além disso, o LD constitui-se como um bem de consumo, que supostamente facilita a aprendizagem do aluno, um produto comercial que, como tal, dispõe de estratégias de marketing para atingir seu público alvo, "marketing esse que se apoia no dizer de especialistas para situar o seu material e divulgá-lo como estando em conformidade com as novas teorias, com os resultados obtidos pelas pesquisas mais recentes" (CORACINI, 1999, p. 37).

Considerando a importância dos LDs e o modo como determinam o ensino nas escolas, torna-se importante observar quais saberes linguísticos ancoram/determinam esse saber/essa materialidade tida como 'inquestionável'. Em nossa reflexão, consideramos o LDP como um discurso sobre a língua, que busca transmitir um saber linguístico construído a partir de determinadas condições de produção.

Tendo em vista nossa perspectiva teórico-metodológica, consideramos, pois, o LDP como um instrumento linguístico, tal como define Auroux (1992). Para o autor, são instrumentos linguísticos a gramática e o dicionário, que representam, por meio da gramatização, a $2^{\mathrm{a}}$ revolução 'tecno-linguística' - sendo a invenção da escrita a $1^{\mathrm{a}}$ revolução. Como já citado anteriormente, ao selecionarmos um objeto de estudo complexo como o LD, há a necessidade de situá-lo como uma materialidade linguística e histórica. Assim, compreendemos que o LDP historiciza um discurso sobre a língua e constitui-se como uma ferramenta com objetivos específicos e explícitos: ensinar/transmitir um conjunto de saberes construídos historicamente. Nesse sentido, defendemos que o LDP é um instrumento linguístico - na denominação de Auroux (1992, p. 69) - visto que, assim como a gramática e o dicionário, permite o "acesso a um corpo de regras e de formas que não figuram junto na competência de um mesmo locutor". 
Ampliando essa noção inicial, Silva Sobrinho (2011, p. 47) afirma que os instrumentos linguísticos "são lugares de representação da língua que nos colocam numa dada relação com a(s) língua(s), com os outros falantes e com o Estado", corroborando com a assertiva de que o LDP é um instrumento linguístico, já que o mesmo abrange as três dimensões elencadas: i) sistematizar, didatizar e historicizar um discurso a respeito da língua; ii) manter relações entre quem produz e quem consome o material didático (nesse caso, é clara a manutenção de relações de distanciamento entre os detentores do conhecimento - os produtores dos LDPs, e os professores utilizadores do material) e; iii) manter perceptível a atribuição do papel do Estado como responsável por adquirir, avaliar e distribuir os LDPs.

Para Orlandi, observar os instrumentos linguísticos como parte de uma complexa relação histórica e social "transforma esses instrumentos em objetos vivos, partes de um processo em que os sujeitos se constituem em suas relações e tomam parte na construção histórica das formações sociais com suas instituições, e sua ordem cotidiana" (2001, p. 8). É por meio desses instrumentos linguísticos, considerados inicialmente apenas como a gramática e o dicionário, que ocorreu o processo de gramatização do Português (SILVA SOBRINHO, 2011, p. 93) e sendo este um conceito relevante para este estudo, compreendemos que "por gramatização deve-se entender o processo que conduz a descrever e a instrumentar uma língua na base de duas tecnologias, que são ainda hoje os pilares de nosso saber metalinguístico: a gramática e o dicionário" (AUROUX, 1992, p. 65). Assim como a gramática e o dicionário são a base do saber metalinguístico, acreditamos também que os mesmos, juntamente com teorias advindas da Linguística, constituem a base teórico-metodológica para a construção dos LDPs.

Partindo dessas considerações, que entendemos serem fundamentais para compreendermos a constituição do LDP, e tendo em vista a relação da HIL com a $\mathrm{AD}$, destacamos, na próxima seção, alguns conceitos da AD que nos auxiliarão em nossa análise.

\section{Sujeito, língua e história: algumas considerações}

Como sabemos, a AD é um campo de estudos que tem como objetivo observar o funcionamento do discurso sob um viés histórico e social, levando em consideração o modo como discurso, sujeito, e ideologia se constituem em uma relação de complementaridade e permuta. AAD constrói seu próprio aparato teórico e metodológico, delimitando conceitos em 
torno de seu objeto de estudo, a saber: o discurso. Para o desenvolvimento deste estudo, selecionamos, dentre o aparato teórico e metodológico da $\mathrm{AD}$, algumas noções que nos auxiliarão na constituição de procedimentos analíticos para análise do corpus discursivo.

O conceito de discurso é o primeiro a ser explicitado e, de certo modo, ocupa uma posição de destaque por fornecer a base para os conceitos que vêm a seguir. Para Pêcheux (2009) e Orlandi (2004; 2015), o discurso é efeito de sentido entre locutores, sendo assim muito mais do que mera transmissão de informações. $\mathrm{O}$ discurso é ainda palavra em movimento, prática de linguagem, realização casual e individual, fato histórico, materialização do sistema linguístico. Orlandi (2015) afirma que "o discurso tem sua materialidade, tem seu funcionamento que é possível apreender se não opomos o social e o histórico, o sistema e a realização, o subjetivo ao objetivo, o processo ao produto" (ORLANDI, 2015, p. 20). Nesse sentido, é importante destacar que o estudo do discurso explicita o modo como sujeito, linguagem e ideologia se articulam e se afetam, numa relação de complementaridade e reciprocidade, pois "não há discurso sem sujeito e não há sujeito sem ideologia” (ORLANDI, 2015, p. 16).

Desse modo, a noção de sujeito é essencial para compreender o discurso e evoca outras noções tais como formação discursiva, ideologia e posição-sujeito (INDURSKY, 2012). Para Pêcheux (2009), a interpelação de um indivíduo em sujeito de seu discurso ocorre pela identificação desse sujeito com uma determinada formação discursiva. Esta identificação, para o autor, "é fundadora da unidade do sujeito" e está apoiada no fato de que os elementos do interdiscurso, que determinam os traços do sujeito, são "reinscritos no discurso do próprio sujeito" (PÊCHEUX, 2009, p. 163). Se, por um lado, estes são traços constitutivos do sujeito discursivo, por outro, é a ideologia que fornece as evidências para a identificação do indivíduo como sujeito do discurso, evidências estas que "fazem com que uma palavra ou enunciado 'queiram dizer o que realmente dizem"” (PÊCHEUX, 2009, p. 160).

Além disso, o sujeito, em função do efeito ideológico que o constitui, apresenta-se como uma posição entre outras, uma posição-sujeito do discurso, numa dada relação com o interdiscurso e em função de uma formação discursiva, que permite observar o modo como o sujeito se significa em dada materialidade (SCHNEIDERS, 2014). Por sua vez, a formação discursiva (FD) é um "domínio de saber, constituído de enunciados discursivos, que representam um modo de relacionar-se com a ideologia 
vigente" (INDURSKY, 2012, p. 11) determinando "o que pode e deve ser dito" (PÊCHEUX, 2009, p. 160), o que pode e deve e o que não pode e não deve ser ensinado.

Como temos observado, a forma-sujeito sempre está inscrita em determinada FD e Pêcheux (2009) considera três modos de subjetivação, ou modos pelos quais o sujeito se relaciona com as FDs: i) o primeiro modo é chamado de identificação plena, no qual o sujeito apresenta um caráter de unicidade com sua FD; ii) o segundo é chamado de contra-identificação e neste modo o sujeito filia-se a um discurso contrário àquele que rege a FD que afeta o sujeito; iii) o terceiro modo recebe o nome de desidentificação e ocorre quando o sujeito realiza uma espécie de migração de uma FD para outra, ou seja, deixa de estar identificado com sua FD de origem.

Para refletirmos sobre o discurso em sua relação com o sujeito e a ideologia, faz-se também necessário observar as condições de produção, que determinam a constituição e a produção de efeitos de sentido no discurso. O conceito de condições de produção possui duas dimensões quanto ao alcance da situação na qual o discurso se materializa: o contexto imediato - da enunciação; e o contexto amplo - sócio, histórico e ideológico (ORLANDI, 2004, p. 150). As condições de produção incluem, de forma inseparável, o sujeito e a situação, do mesmo modo que não se pode separar o contexto imediato do contexto amplo em que determinado discurso ocorre, pois os dois atuam de forma conjunta na produção de sentidos.

A partir das condições de produção do discurso, podemos compreender, igualmente, a maneira como o processo discursivo é constituído por discursos já ditos que ressoam na formulação do discurso por meio do interdiscurso. Este, por sua vez, é referido por Orlandi (2004) como o lugar no qual

[...] se explicita o processo de constituição do discurso: a memória, o domínio do saber, os outros dizeres já ditos ou possíveis que garantem a formulação (presentificação) do dizer, sua sustentação. Garantia de legibilidade e de interpretação: para que nossas palavras façam um sentido é preciso que (já) signifiquem. Essa impessoalidade do sentido, sua impressão referencial, resulta do efeito de exterioridade: o sentido lá. A objetividade material contraditória (ORLANDI, 2004, p. 39).

Pelo interdiscurso compreendemos a memória discursiva que afeta a materialidade discursiva analisada, apontando para determinados efeitos de sentido que se vinculam à conjuntura sócio-histórica e ideológica 
na qual sujeito e discurso se inscrevem. O discurso passa a ser compreendido, então, como unidade de sentido, quando relacionado a suas condições de produção e aos discursos já-ditos, mas esquecidos, que ancoram o dizer e a produção de efeitos de sentido.

Por meio dessa relação com a exterioridade, podemos, também, compreender a historicidade do discurso. O conceito de historicidade explicita a relação do discurso com sua a exterioridade - com a história. Para Orlandi (2015, p. 46), "nem a linguagem, nem os sentidos nem os sujeitos são transparentes: eles têm sua materialidade e se constituem em processos que a língua, a história e a ideologia concorrem conjuntamente", resultando em um processo no qual os sentidos são determinados pela história e os sujeitos são constituídos pela ideologia.

Assim, os conceitos aqui elencados nos auxiliam a observar o modo como o desenvolvimento das ideias (teorias) linguísticas estão materializadas no fio do discurso, determinando a constituição dos LDPs, e a explicitar a posição-sujeito inscrita nos materiais didáticos e a complexa teia discursiva que é traço fundamental de toda materialidade discursiva. Essas questões teóricas constituem o dispositivo teórico e analítico que norteiam o presente estudo e os gestos interpretativos que nos propomos a realizar.

\section{Entre o descrever e o interpretar: gestos de inter- pretação sobre o LDP}

Para este estudo, selecionamos dois exemplares de Livros Didáticos de Língua Portuguesa. O Livro 1 (L1), de circulação atual (critério 1 (um) para seleção da materialidade), com vigência 2014-2016 e com larga utilização nas escolas da região é o livro Português - Linguagens - $9^{\circ}$ Ano, de William Roberto Cereja e Thereza Cochar Magalhães. Para a escolha desse livro, levamos em consideração o fato de o mesmo figurar entre as coleções mais distribuídas nos anos recentes, tendo sido a primeira da lista nos anos de 2014 e 2015. Definimos como critério 2 (dois), para a seleção da materialidade, a publicação num período anterior ao início da vigência dos Parâmetros Curriculares Nacionais (BRASIL, 1997) - PCNs, tendo em vista que este documento representa um marco para o ensino de LP, ao propor um enfoque de ensino com base em teorias linguísticas, buscando se afastar de uma perspectiva de ensino tradicional. Desse modo, o Livro 2 (L2), que também teve circulação nas escolas da região, é o livro Reflexão e Ação em Língua Portuguesa - $8^{\mathrm{a}}$ Série, de 
Marilda Prates. Esse livro foi publicado na década de 1980 e teve várias reedições durante essa década e a seguinte, demonstrando ter obtido um bom sucesso editorial. A referência mais recente desta materialidade, porém com título atualizado, em documentos oficiais, foi encontrada no Guia do PNLD do ano de 2005, explicitando mais uma vez o sucesso de circulação e consumo obtido pelo livro.

Nosso corpus de análise ficou assim constituído por dois LDPs, a partir dos quais selecionamos marcas linguísticas que nos permitem explicitar a maneira como as teorias linguísticas ressoam na discursividade dos LDs em análise. Os procedimentos analíticos, necessários para lançarmos gestos de interpretação sobre o corpus de análise, foram realizados com base em movimentos pendulares, que vão da teoria para a análise e da análise para a teoria, passando pelo analista do discurso.

Para Petri (2013, p. 42), é no "movimento de ir e vir que o pêndulo agita os processos de produção de sentidos sobre o corpus", fazendo com que se construam sentidos em qualquer parte do movimento e evite-se a estagnação do processo de análise. Ainda nesse sentido, há que se considerar que, tal qual o pêndulo real, o movimento realizado ocorre em um espaço passível de interferências, imperfeições e resistências, as quais interferem na análise do discurso justamente por ser este um trabalho com materialidades incompletas e, por vezes, contraditórias.

\section{Dos gestos de interpretação}

Em nossa perspectiva, para o analista do discurso, interpretar é realizar um constante movimento pendular entre a teoria base e o corpus de pesquisa e é por meio deste movimento que os gestos interpretativos vão sendo construídos. Em nossos gestos interpretativos, explicitamos, num primeiro momento, a construção da materialidade linguística, para, em seguida, observarmos sua constituição e funcionamento, retornando para a teoria base sempre que necessário. Sendo assim, o L1 tem quatro unidades, dentre as quais tomamos a primeira como nosso objeto de estudo.

Temos interesse em observar, em primeiro lugar, quais ideias linguísticas ressoam no fio do discurso dos LDs, porém é necessário que façamos referência à escolha temática dos autores na seleção dos textos que são objeto de estudo das unidades e capítulos dos livros, devido a esta seleção estar ancorada nas condições de produção das materialidades, além de explicitar o modo como a historicidade determina os efeitos de sentido dentro dos LDs. A seleção de temas indica o que os autores, e, por conse- 
guinte, todo o aparato estatal, acreditam serem questões importantes para a formação dos alunos. Esses temas interferem nas atividades solicitadas no seguimento do capítulo e na constituição dos LDs. Assim, a Unidade 1 do L1 tem como título "Valores" e o Capítulo 1 tem como título "O preço de estar na moda", temas relevantes da sociedade contemporânea e que possibilitam a reflexão sobre uma forma-histórica do sujeito moderno, a forma-sujeito capitalista (PÊCHEUX, 2009), que possibilita que os indivíduos tenham sua liberdade e autonomia, mas que não permite que o sujeito escape à determinação do Estado que o controla e responsabiliza por seus atos (SCHNEIDERS, 2014). Os textos selecionados para a unidade são "Moda tem de parar de sacrificar modelos", de Alcino Leite e Vivian Whiterman, e "Plástica na adolescência", de Fabiana Gonçalves. Por meio de textos críticos a preceitos capitalistas de consumo e padrões de beleza, compreendemos que o L1 é determinado pelas suas condições de produção - a crítica ao sistema vigente - e também pelo Estado que, do mesmo modo, ocupa uma posição ideológica crítica em relação ao sistema capitalista.

Passamos a observar, então, as seções do Capítulo 1: Estudo dos textos; Produção de texto; Para escrever com expressividade; A língua em foco; De olho na escrita; e Divirta-se. Nas três primeiras seções, há um esforço no sentido de atender as diretrizes dos PCNs (1997), que propõem que o ensino de Língua Portuguesa e a organização dos conteúdos para o ensino sejam articulados em três eixos: leitura, produção textual e análise linguística. A primeira seção é dividida nas subseções "Compreensão e interpretação", "A linguagem dos textos" e "Trocando ideias", a primeira subseção tem como foco a análise dos textos e a retirada de informações da superfície textual, a segunda visa à ampliação de léxico e à observação do estilo de escrita dos textos, e a terceira busca propor a reflexão sobre o tema, trazendo questões nas quais o aluno deverá explicitar sua opinião a respeito do tema.

A segunda seção tem uma única subseção com o título "A reportagem", na qual o aluno é motivado a ler e a produzir uma reportagem, reforçando a proposta dos PCNs (1997), que afirmam que o estudo da língua deverá ter como base os gêneros discursivos/textuais e como objeto de análise o texto. Para tanto, os PCNs (1997) afirmam que os textos se organizam dentro de determinados gêneros e que os vários gêneros existentes constituem formas relativamente estáveis de enunciados disponíveis na cultura, caracterizados por três elementos: conteúdo temático, 
estilo e construção composicional. Essa perspectiva explicitada nos PCNs (1997) tem sua raiz na teoria dos gêneros do discurso de Mikhail Bakhtin (2003) e, mais recentemente, nas proposições dos linguistas Bernard Schneuwly e Joaquim Dolz (2004), que utilizam a teoria dos gêneros textuais como aporte metodológico para o ensino. Nessas seções, a filiação do discurso do LD aos saberes do domínio da perspectiva dos gêneros discursivos - que, como dissemos, é uma dentre outras perspectivas de ensino de língua - reporta-se a um conhecimento constituído pelo domínio de memória da Linguística ${ }^{3}$, ao mesmo tempo em que atende às diretrizes do Estado, que primeiramente adotou essa perspectiva.

A terceira seção do capítulo 1 tem como subseção "O discurso citado nos textos jornalísticos" e propõe uma análise textual/discursiva do texto base da subseção, de modo que o aluno possa identificar quais vozes ecoam nos discursos jornalísticos. As atividades desta seção realizam uma análise linguística do texto e atendem às orientações dos PCNs (1997) quanto a este tipo de atividade. Vemos assim, o modo como o Estado, via PCNs (1997), determina o que pode e deve ou não ser ensinado, mas também o que escapa a essa determinação, como vemos a seguir.

Se até o momento observamos um esforço por manter um fio condutor do discurso que buscasse atender às orientações dos documentos normatizadores do ensino de língua em nosso país, vemos que, nas demais seções do capítulo, os autores fazem um rompimento com esta perspectiva. Na seção "A língua em foco", observamos claramente que o foco será a gramática normativa e de forma totalmente desconectada de textos trabalhados anteriormente. A subseção "As orações subordinadas substantivas" tem como tópicos: Classificação das orações substantivas; Orações substantivas reduzidas; As orações substantivas na construção do texto; e Semântica e discurso.

Nessa subseção são ofertados pequenos textos que servem como pretexto para o ensino de gramática em uma perspectiva tradicional, com a utilização de metalinguagem e com foco na correção linguística, propondo-se a definir regras para a instrumentalização e utilização da língua, tal qual o dicionário e a gramática. Mesmo o terceiro tópico, que faz referência ao texto, não se diferencia dos demais quanto ao foco do estudo. $\mathrm{O}$ último tópico "Semântica e discurso", em seu título, nos remete à própria $\mathrm{AD}$, que busca observar os efeitos de sentido no discurso, mas o que observamos de fato é apenas a continuidade do ensino de gramática.

A seção seguinte, "De olho na escrita", tem como subseção "Plu- 
ral dos substantivos compostos" novamente dá seguimento ao ensino de gramática e busca explicitar o conjunto de regras do conteúdo abordado, cabendo ao aluno a tarefa de memorizar essas regras. Por fim, a última seção propõe uma pequena brincadeira em forma de uma charada e não apresenta conexão alguma com os tópicos abordados no capítulo.

Ao analisarmos o L1, pudemos observar que a questão do sentido e do discurso como uma produção linguístico-histórica e ideológica acaba sendo silenciada, como vimos no tópico "Semântica e discurso", mantendo-se a ideia da estabilização dos sentidos, tal qual em um dicionário (PETRI, 2010). Além disso, cabe destacarmos que a posição-sujeito inscrita no discurso vincula-se a uma FD do gramático, no entanto, em função das condições de produção e das diretrizes do Estado, são trazidos determinados discursos para o LD, no caso, o discurso dos gêneros discursivos. Isso não causa, porém, uma desidentificação do sujeito com sua FD, o que ocorre é um trânsito entre os saberes da mesma e de outras FDs. Neste sentido, o ensino com base em gêneros discursivos está vinculado a FD do gramático, pois mesmo com objetos de ensino e enfoques diferentes, permanece o caráter transversal da gramática.

Em continuidade, passamos a observar a constituição discursiva do L2 que é representativo de um importante momento histórico de nosso país, ou seja, é fortemente determinado pela historicidade. O L2 foi publicado no ano de 1984, no período final da ditadura militar, e o conturbado momento social e político do país - as condições de produção do discurso - é explicitado por meio da escolha do texto principal da Unidade 1, "Política e Politicalha", um texto argumentativo do autor Rui Barbosa, que provoca efeitos de sentido que trazem à tona a reflexão sobre o modo como é conduzida a gestão do Estado.

Nesse período, iniciavam-se no Brasil as reflexões sobre a leitura e escrita em sala de aula. Os textos do linguista brasileiro João Wanderlei Geraldi são importantes marcos para o ensino de Língua Portuguesa e trazem pela primeira vez o reconhecimento do texto como objeto de ensino e da necessidade de ensinar os alunos a ler e escrever de forma efetiva, tendo em vista o fracasso da perspectiva tradicional de ensino, com foco na gramática e na metalinguagem, em formar leitores e produtores textuais competentes. Em sua obra o "O texto em sala de aula”, Geraldi (1984) explicita concepções de linguagem relacionadas a diferentes correntes de estudos linguísticos. Essas concepções compreendem a linguagem como: i) expressão do pensamento: correspondente aos estudos da gramática 
tradicional; ii) instrumento de comunicação: ligada ao estruturalismo e o transformacionalismo; iii) forma de interação: ligada à linguística da enunciação.

No L2, observamos uma forma distinta de apresentação da grade de conteúdos. O índice é apresentado de forma simplificada e um detalhamento maior das atividades de cada unidade é apresentado como uma página inicial da mesma. Assim, a Unidade 1 (de um total de 12) apresenta as seções principais como "Texto 1: Política e Politicalha" e "Texto 2: Rondó dos Cavalinhos", cada qual com sua própria subdivisão. O Texto 1 possui as subseções: Estudo do vocabulário; Vamos discutir o texto; A sua interpretação crítica do texto; Estudo gramatical; Estudo da ortografia; Para compreender e fixar.

Todas essas seções são também segmentadas em subseções. Após a leitura do texto, passa-se à primeira subseção, com o título "Estudo do vocabulário", que tem como objetivo promover a ampliação de léxico do aluno por meio do estudo de sinônimos, categorias de sentido e palavras cognatas. As duas subseções seguintes - "Vamos discutir o texto" e "A sua interpretação crítica do texto" - buscam ampliar a compreensão do texto lido por meio de conceitos discursivos e de questões relacionadas ao texto, sendo na terceira subseção questões de caráter subjetivo, nas quais os alunos deverão expressar sua opinião. As três seções seguintes tomam um grande espaço no qual o foco é o ensino da gramática normativa por meio de conceitos que deverão ser memorizados e de exercícios construídos a partir de frases desconectadas dos textos da unidade. Aqui, assim como em grande parte do livro anterior, a proposição é definir regras para a instrumentalização e utilização da língua, tal qual o fazem o dicionário e a gramática. Do mesmo modo, a posição-sujeito do discurso do L2 se identifica a uma FD dos saberes gramaticais.

A seção 2 tem como título e texto base "Rondó dos Cavalinhos" e sua primeira subseção é "Atividades de reflexão e conclusão". Nessas atividades, são realizadas a localização de informação textual explícita e o estudo de conceitos advindos da literatura, como prosa e verso, e da linguística, como função poética. Esse último conceito nos remete aos estudos de viés comunicativo de Roman Jakobson (2010), sendo a função poética uma das funções da linguagem expostas pelo autor. Para Jakobson (2010, p. 151), "A Poética trata dos problemas da estrutura verbal, assim como a análise de pintura se ocupa da estrutura pictorial. Como a Linguística é a ciência global da estrutura verbal, a Poética pode ser en- 
carada como parte integrante da Linguística". O objetivo desta subseção é proporcionar a leitura de um texto do cânone literário e utilizá-lo como base para a compreensão dos conceitos citados acima. A referência feita aos estudos de viés comunicativo explicita o modo como o discurso é afetado pela exterioridade, pela sua historicidade, tendo em vista a relevância que tais estudos tiveram no período em que o L2 foi produzido. Isso demonstra também um período de transição, momento em que a ideia de linguística como um código para comunicação e expressão mostrou-se insuficiente e possibilitou a abertura de espaço para os estudos da Linguística Textual. Essa transição é perceptível, pois observamos marcas que se vinculam ao viés comunicativo - como acabamos de ver - e, após, surge referência às questões teóricas da Linguística Textual, como vemos no próximo parágrafo.

A subseção seguinte tem como título "Reflexão e ação mental" e, na mesma, são colocadas algumas frases/citações que deverão levar o aluno a refletir sobre questões políticas e sociais. Devido ao seu caráter sociocomunicativo, podemos caracterizar tais citações como textos, como unidades de sentido, o que nos remete à Linguística Textual que, busca integrar o estudo de aspectos linguísticos, sociocognitivos, interacionais e culturais (KOCH, 1997). Os estudos da Linguística Textual tiveram grande impacto sobre o ensino de Língua Portuguesa e sobre a produção de materiais didáticos na década de oitenta $(\mathrm{KOCH}, 1997)$, o que mais uma vez explicita o modo como as condições de produção e a historicidade afetam o discurso dos sujeitos e, em consequência, o que será ou não ensinado nas escolas.

Por fim, a subseção "Atividades de redação" encerra a primeira unidade do L2 e, como o próprio nome sugere, propõe a escrita de um texto. Na descrição das atividades, que podem ser encontradas logo abaixo do título, o autor apresenta as seguintes assertivas em forma de pergunta e resposta:

Por que fazer redações?

Para desenvolver a capacidade de expor, com clareza, elegância e correção as suas ideias.

Assim como descreve Geraldi (1984), a perspectiva aqui encontrada pertence a uma concepção de linguagem como expressão do pensamento, que corresponde aos estudos da gramática tradicional. Além disso, nesta subseção ocorre uma mescla de atividades que propõem que o aluno obedeça a regras de pontuação, atenha-se a conceitos da gramática, escre- 
va com criatividade e leve em consideração conceitos de tipologia textual, de modo a escrever seu texto de forma adequada. Os conceitos de tipologia textual são oriundos da Linguística Textual, foram parte da elaboração das gramáticas textuais e atualmente ocupam, sob o enfoque dos gêneros textuais, um lugar de destaque nas pesquisas sobre o texto (KOCH, 1997).

Tendo em vista essa composição e enfoque das unidades dos LDs tomados como corpus de análise, entendemos que o sujeito do discurso se inscreve em uma FD que se vincula aos saberes gramaticais, mas circula entre os diferentes saberes sobre a língua, conforme as condições de produção de seu discurso. Consideramos isso, pois, mesmo que observemos referências às teorias linguísticas, o que predomina na discursividade é o discurso da gramática, materializado pelo enfoque no ensino de regras gramaticais.

Há outros fatores que perpassam e determinam a constituição dos mesmos, como o fato de os LDs serem um bem de consumo com obsolescência programada (os livros são utilizados por três anos e, após este período, substituídos, mesmo que por edições mais atuais do mesmo livro). Os LDs são produtos editorias destinados ao consumo por professores e alunos da educação básica e são comprados e distribuídos predominantemente pelo Estado, o que nos leva a refletir sobre questões ideológicas e de poder. Assim, estar ideologicamente alinhado com o Estado, principal comprador do produto, é um dos critérios para receber um parecer favorável por parte do PNLD e aumentar as chances do LD ser selecionado para compra.

Outro elemento considerado é a diferença entre as publicações, que é de 28 anos (L1: 2012; L2: 1984), e esperávamos grandes diferenças entre os LDs, o que de fato ocorre em vários pontos, como na escolha e seleção de temas e textos. Surpreende-nos, porém, o fato de um livro atual como L1 manter uma perspectiva de ensino estritamente gramatical em algumas seções, indo em direção totalmente contrária às diretrizes nacionais. Para os PCNs (1997), deverá ser priorizada, num primeiro momento, a utilização de atividades epilinguísticas - reflexão sobre os fenômenos e estruturas linguísticas em função dos usos e da produção de sentido - em detrimento das atividades metalinguísticas, mas sem excluí-las, direção oposta à tomada pelo L1. A presença dessa perspectiva de ensino dentro dos LDs, com maior enfoque no L2 e menor no L1, explicita uma concepção de língua como sistema de regras e uma concepção de ensino cujo foco é o saber gramatical. 
Para finalizar nossos gestos interpretativos, destacamos que o interdiscurso é um todo e que as FDs se reportam somente a uma parte do mesmo, constituindo-se em uma área de saberes específicos, que dialoga com outros saberes. Observamos que, devido às condições de produção dos LDs analisados, determinadas teorias linguísticas ressoam de forma mais expressiva na discursividade dos LDs, afetando sua constituição: as teorias dos gêneros discursivos, que afetam parte da constituição do L1; a linguística textual, que afeta parte da constituição do L2. Apesar de marcados pela exterioridade, pelas teorias linguísticas que propõem avanços e alternativas para o ensino, os LDPs analisados não rompem com a tradição do ensino de LP que historicamente é voltada para elementos gramaticais, com a utilização de metalinguagem e com foco na correção linguística, propondo-se a definir regras para a instrumentalização e utilização da língua, tal qual o dicionário e a gramática. Assim, vemos que é a FD do gramático que historicamente constitui o sujeito inscrito nos LDs, pois, mesmo que se busquem alternativas para o ensino, o mesmo sempre está inscrito no viés tradicional de ensino de língua.

\section{Considerações finais}

Em nosso estudo, realizamos gestos interpretativos que permitem a observação e explicitação da maneira como o desenvolvimento das ideias (teorias) linguísticas estão materializadas no fio do discurso, determinando a constituição dos LDPs, e em quais concepções de língua e linguagem, sujeito e ensino a produção dos LDPs encontram-se ancorados. Ao longo de nossas reflexões, explicitamos determinados saberes do domínio de memória da Linguística - o interdiscurso, que ressoam na discursividade dos livros analisados, determinando certos efeitos de sentido, com destaque para as teorias dos gêneros discursivos e as teorias da Linguística Textual, que são parte da historicidade e das condições de produção dos LDPs.

Retomamos Orlandi (2015, p. 16), que afirma que "não há discurso sem sujeito e não há sujeito sem ideologia", e Pêcheux (2009, p. 160), que afirma que a FD e a ideologia determinam "o que pode e deve ser dito". A partir destes preceitos, destacamos que as materialidades analisadas apresentam semelhanças e diferenças. Nesse ponto, as diferenças observadas são resultado das diferentes condições de produção e determinações ideológicas, sob as quais foram submetidos os LDs, e são esses elementos que determinam, por exemplo, a temática dos textos que 
circulam no interior de cada livro - no L2, um texto sobre política, no período final da ditadura militar; no L1, a seleção textos reafirmando a posição ideológica do Estado.

Reafirmando os LDs como materialidades linguísticas significantes e como um dos meios pelos quais o Estado mantém o controle ideológico sobre o que pode e deve e o que não pode e não deve ser ensinado nas escolas, destacamos que permanece nos LDs uma forte presença do ensino com enfoque na gramática, mesmo com todos os avanços das teorias linguísticas. Além disso, os LDs explicitam uma concepção de língua como sistema de regras, uma concepção de linguagem, em alguns momentos, como expressão do pensamento, em outros como instrumento de comunicação, e uma concepção de ensino cujo foco é o saber gramatical, evidenciando que as materialidades selecionadas para análise fazem parte de uma Formação Discursiva de saberes gramaticais.

Por fim, acreditamos que o LDP deve ser pensado como uma materialidade linguística e histórica, que não está desvinculada das suas condições de produção, sendo afetado e determinado pelo que é posto em circulação referente ao conhecimento linguístico. Do mesmo modo, essa materialidade está vinculada à forma sujeito histórica, à ideologia vigente e aos demais elementos que compõem o fio do discurso. 


\section{THE CONSTITUTION OF TEXTBOOKS BY DETERMI- NATION FROM LINGUISTIC THEORIES}

\section{ABSTRACT}

In the present study, we analyze how linguistic theories are retaken and articulated in the discursive constitution of didactic materials destined to the teaching of Portuguese Language in Brazil. We seek to make explicit, through linguistic marks, the way these linguistic theories resonate in the discursivity of these materials. Our corpus of analysis consists of two textbooks of the Portuguese Language: i) a current circulation copy - Português Linguagens - $9^{\circ}$ Ano, by William Roberto Cereja and Thereza Cochar Magalhães; ii) a copy from the eighties - Reflexão e Ação em Língua Portuguesa - 8 a Série, by Marilda Prates. We understand the examples as significant linguistic materialities in order to understand their constitution and how they affect and determine what can and should be taught in Portuguese language classes and in schools. In order to do so, we are bound to the presuppositions of the History of Linguistic Ideas, which in Brazil is linked to the Discourse Analysis from Pêcheux, and which helped us to perform interpretive gestures on the corpus. Based on the analysis, we consider the Textbooks linguistic instruments, and we understand that this materiality has a strong presence of teaching with a focus on traditional grammar, even with all the advances of linguistic theories.

KEYWORDS: Discourse analysis. Textbooks. History of linguistic ideas.

\section{NOTAS}

${ }^{1}$ Este estudo é resultado do trabalho de conclusão de curso (TCC) do referido acadêmico.

${ }^{2}$ Este conceito é entendido a partir de Althusser (1985). 
${ }^{3}$ Por domínio de memória da linguística, compreendemos o conhecimento construído em torno desta ciência, a partir do século XX, com Ferdinand de Saussure.

\section{REFERÊNCIAS}

AUROUX, Sylvain. A revolução tecnológica da gramatização. Tradução de Eni Puccinelli Orlandi. Campinas: Editora da UNICAMP, 1992.

BAKHTIN, Mikhail. Os gêneros do discurso. In: . Estética da criação verbal. 4.ed. SP: Martins Fontes, 2003. p. 261-306.

BRASIL. Ministério da Educação. Parâmetros curriculares nacionais: língua portuguesa. Brasília, 1997. Disponível em: http://portal.mec.gov.br/seb/arquivos/ pdf/livro02.pdf. Acesso em 05 mar. de 2016.

CEREJA, William Roberto; MAGALHÃES, Thereza Cochar. Português: Linguagens. $9^{\circ}$ ano. 7. Ed. Reform. SP: Saraiva, 2012.

CORACINI, Maria José Rodrigues Faria (Org.). Interpretação, Autoria e Legitimação do Livro Didático: língua materna e língua estrangeira. $1^{\mathrm{a}} \mathrm{ed}$. - Campinas, SP: Pontes, 1999.

GERALDI, João Wanderley. (Org.). O texto na sala de aula. SP: Ática, 1984.

INDURSKY, Freda. Unicidade, desdobramento, fragmentação: a trajetória da noção de sujeito em análise do Discurso. In: Práticas discursivas e identitárias. Sujeito e língua. MITTMANN, Solange, GRIGOLETTO, Evandra e CAZARIN, Ercília Ana. Porto

Alegre: Nova Prova Editora, 2008. p. 9-33.

JAKOBSON, Roman. Linguística e Comunicação. Tradução Izidoro Blikstein e José Paulo Paes. 22 ed. São Paulo: Cultrix, 2010.

KOCH, Ingedore Grunfeld Villaça. Lingüística Textual: Retrospecto e Perspectivas. Alfa, São Paulo, 41: 67-78, 1997.

ORLANDI, Eni Puccinelli. História das Ideias Linguísticas. Campinas-Cáceres: Pontes-Unemat, 2001.

Interpretação: autoria, leitura e efeitos do trabalho simbólico. 4. ed. Campinas, Editora Pontes, 2004.

. Análise de Discurso. In: LAGAZZI-RODRIGUES, Suzy. (Org.). Introdução às Ciências da Linguagem: Discurso e Textualidade. Campinas, SP: Pontes Editores, 2006. 
. Discurso e Texto: formulação e circulação de sentidos. 2. ed. Campinas, Editora Pontes, 2008.

. Análise do discurso: Princípios e procedimentos. 3. ed. Campinas, Editora Pontes, 2015.

PÊCHEUX, Michel. Semântica e Discurso: uma crítica à afirmação do óbvio. 4. ed. brasileira. Tradução Eni Orlandi et al., SP: Campinas, Editora da Unicamp, 2009.

PETRI, Verli. Um outro olhar sobre o dicionário: a produção de sentidos. 1. ed. Santa Maria: UFSM, PPGL-Editores, 2010.

. O Funcionamento do Movimento Pendular Próprio às Análises Discursivas na Construção do "Dispositivo Experimental" da Análise do Discurso. In: PETRI, Verli. DIAS, Cristiane (Org.). Análise de Discurso em Perspectiva - Teoria, método e análise. Santa Maria: Editora da UFSM, 2013.

PRATES, Marilda. Reflexão e Ação em Língua Portuguesa. SP: Ed. Atual, 1984.

SILVA SOBRINHO, José Simão. "A língua é o que nos une": língua, sujeito e Estado no Museu da Língua Portuguesa. Tese (Doutorado em Letras) - Universidade Estadual de Campinas, Instituto de Estudos da Linguagem, Campinas, SP: [s.n.], 2011.

SCHNEIDERS, Caroline Mallmann. Serafim Da Silva Neto: entre a constituição e a circulação do conhecimento linguístico. Tese (Doutorado em Letras) Universidade Federal de Santa Maria, Santa Maria, 2014.

SCHNEUWLY, Bernard.; DOLZ, Joaquim. Gêneros orais e escritos na escola. Tradução Roxane Rojo e Glaís Sales Cordeiro. SP: Mercado de Letras, 2004, p. 95-128.

SOARES, Magda. Português na escola: História de uma disciplina curricular. In: BAGNO, M. Linguística da norma. 2 ed. SP: Edições Loyola, 2000.

Recebido em: 01/02/2017

Aceito em: 12/06/2017 